\title{
Group treatment plus usual care decreased the risk of deliberate self harm in adolescents who repeatedly harm themselves
}

Wood A, Trainor G, Rothwell J, et al. Randomized trial of group therapy for repeated deliberate self-harm in adolescents. J Am Acad Child Adolesc Psychiatry 2001 Nov;40:1246-53.

QUESTION: In adolescents who repeatedly harm themselves, is group treatment plus usual care more effective than usual care alone for decreasing depression and risk of deliberate self harm?

Source of funding:

Mental Health

Foundation.

For correspondence: Dr R Harrington,

Royal Manchester

Children's Hospital,

Pendlebury, Manchester

UK.r.c.harrington@

man.ac.uk

\section{Design}

Randomised (allocation concealed)*, blinded (outcome assessors),* controlled pilot study with 7 months of follow up.

\section{Setting}

Withington Hospital, South Manchester, UK.

\section{Patients}

63 patients who were 12-16 years of age (mean age 14 y, $78 \%$ girls) and referred to a child and adolescent mental health service in South Manchester, UK after an incident of deliberate self harm and who reported $\geqslant 1$ other occasion of deliberate self harm during the previous year. Exclusion criteria included cases of accidental drug overdoses or any alcohol overdose, those who were considered too suicidal for outpatient care, and those who suffered from a psychotic disorder. Follow up was $98 \%$.

\section{Intervention}

Patients were allocated to group treatment plus usual care $(n=32)$ or to usual care alone $(n=31)$. Group treatment comprised an initial assessment phase, attendance at 6 acute group sessions oriented around 6 themes (relationships, school problems and peer relationships, family problems, anger management, depression and self harm, and hopelessness and feelings about the future), and followed with weekly group treatment in a long term group (places more emphasis on group processes), until the patient felt ready to leave. Acute and long term group sessions, administered by a senior nurse and a psychiatrist, ran continuously and patients could join them at any time. Usual care consisted of a variety of interventions given by community psychiatric nurses and psychologists, including family sessions, non-specific patient counselling, and psychotropic medication when clinically indicated.

\section{Main outcome measures}

Self reported repeating self harm, depressive symptoms, and suicidal thinking.

\section{Main results}

Analysis was by intention to treat. Risk of repeating self harm was lower in group treatment plus usual care than in usual care alone (table). Groups did not differ for decreases in depression or suicidal thinking (table).

\section{Conclusion}

In adolescents who repeatedly harm themselves, group treatment plus usual care was more effective than usual care alone for decreasing the risk of deliberate self harm, but groups did not differ for decreases in depression or suicidal thinking.

*See glossary.
Group treatment plus usual care v usual care in adolescents who repeatedly harm themselvest

\begin{tabular}{|c|c|c|c|c|}
\hline Outcomes at 7 months & $\begin{array}{l}\text { Group } \\
\text { treatment }\end{array}$ & $\begin{array}{l}\text { Usual } \\
\text { care }\end{array}$ & RRR (95\% CI) & NNT (Cl) \\
\hline \multirow[t]{3}{*}{ Repeating self harm } & $6 \%$ & $32 \%$ & $78 \%$ (22 to 96$)$ & $4(3$ to 14$)$ \\
\hline & \multicolumn{2}{|c|}{$\begin{array}{l}\text { Mean change in score } \\
\text { from baseline }\end{array}$} & \multirow[b]{2}{*}{ Difference $(\mathrm{Cl})$} & \\
\hline & $\begin{array}{l}\text { Group } \\
\text { treatment }\end{array}$ & $\begin{array}{l}\text { Usual } \\
\text { care }\end{array}$ & & \\
\hline $\begin{array}{l}\text { Decrease in depressive } \\
\text { symptoms } \neq\end{array}$ & 19 & 15 & $3.5(-4.4$ to 11$)$ & \\
\hline $\begin{array}{l}\text { Decrease in suicidal } \\
\text { thinking§ }\end{array}$ & 47 & 40 & $7.5(-19$ to 34$)$ & \\
\hline
\end{tabular}

†Abbreviations defined in glossary; RRR and corresponding $\mathrm{Cl}$ calculated from data in article. Mood and Feelings Questionnaire, score range 0 to 68; higher score=greater depression. §Suicidal Ideation Questionnaire, score range 0 to 180; higher score=higher suicidal ideation.

\section{COMMENTARY}

Managing and treating adolescent suicidal behaviour is a substantial challenge for clinicians and the lack of empirical data influences treatment decisions. Treatment outcome studies and clinical approaches specifically designed for suicidal behaviour, such as this study by Wood et al, are important contributions to the research literature.

This study has several noteworthy features. Firstly, the researchers specifically designed a rolling admissions format, which makes it more feasible for this group treatment approach to be used in clinic settings. Secondly, the group treatment plus usual care showed a decrease in repeat suicide attempts compared with usual care, despite the fact that these adolescents had a history of multiple suicide attempts and substantially higher levels of psychopathology and substance abuse than typically seen in first time attempters. These findings bode well for the clinical significance of the study.

However, we do not know whether such an intervention is necessary for first time attempters or whether iatrogenic effects of treatment, interestingly absent in this sample, might arise in group treatments with first time attempters. Future research will need to address which treatment approaches work best for which subgroups of adolescent suicide attempters.

The design of the study does not permit us to understand whether both treatments, acute group with skills training and long term process oriented group, are necessary to reduce suicidal behaviour or whether being involved in any type of group treatment for an extended period of time is effective. The lack of effects on depressed mood and suicidal thinking suggests that future research should examine a more comprehensive treatment approach to also address underlying psychiatric conditions as well as the suicidal behaviour itself.

Because of the potentially serious consequences of a false negative prediction (ie, missing attempters who go on to repeat self harm), we need to provide at least a minimal intervention to all adolescent suicide attempters. The group treatment approach shown by Wood $e t$ al may be a beneficial avenue for clinicians to pursue because it had a very significant effect on decreasing the rate of repeating self harm compared with even adequate doses of usual care.

Anthony Spirito, $\mathrm{PhD}$ Brown Medical School Providence, Rhode Island, USA 